\title{
A Exigência de Novos Padrões no Ensino Jurídico Frente as Novas Tecnologias
}

CHICHERA, Maria Angélica ${ }^{1}$

\section{RESUMO}

O presente artigo tem por objetivo abordar questões no que dizem respeito aos recursos de aprendizagem utilizados nas salas de aula e a inclusão das novas tecnologias no ensino jurídico, como mais uma opção de ferramenta a ser implementada no processo de ensino e aprendizagem. Importante se faz, verificar se há a compreensão pelos docentes do Direito das reais tendências para o futuro e se os efetivos impactos que as novas tecnologias têm revolucionado o mundo escolar e de como elas estão modificando o modo de pensar e agir dos agentes envolvidos no processo ensino-aprendizagem, numa sociedade globalizada e informatizada. Por se tratar de um estudo descritivo e hipotético, será realizado com base na pesquisa bibliográfica e histórica, utilizando-se do método indutivo.

Educação Jurídica. Tecnologia. Docente. Ensino Jurídico. Novas Formas de Aprendizagem.

\section{The demand of new patterns in legal education in front of new technologies}

\begin{abstract}
The aim of this article is to address questions regarding learning resources used in classrooms and the inclusion of new technologies in legal education, as a further option of a tool to be implemented in the teaching and learning process. It is important to verify if there is an understanding by law teachers of the real tendencies for the future and if the effective impacts that the new technologies have revolutionized the school world and how they are modifying the way of thinking and acting of the agents involved in the process teaching-learning, in a globalized and computerized society. Because it is a descriptive and hypothetical study, it will be carried out based on bibliographical and historical research, using the inductive method.
\end{abstract}

\footnotetext{
1 Doutoranda em Direito pela Pontifícia Universidade Católica de São Paulo - PUC-SP. Mestre em Direito pela Universidade Nove de Julho. Vice-Presidente da Comissão de Processo Civil na Subseção de Santo André-OAB/SP. E-mail: gelichichera@yahoo.com.br. Lattes: http://lattes.cnpq.br/6078562251271927. Orcid: https://orcid.org/0000-0002-2613-7174.
}

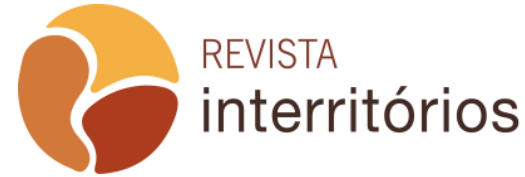


Legal Education. Technology. Teacher. Legal Teaching. New Forms of Learning.

\section{La demanda de nuevos patrones en educación jurídica frente a las nuevas tecnologías}

\section{RESUMEN}

Este artículo tiene como objetivo abordar cuestiones relativas a los recursos de aprendizaje utilizados en las aulas y la inclusión de las nuevas tecnologías en la enseñanza jurídica, como una opción más de herramienta que puede ser implementada en el proceso de enseñanza y aprendizaje. Es importante comprobar si existe un entendimiento por parte de los profesores de Derecho de las tendencias reales para el futuro, si tienen idea de los impactos efectivos que las nuevas tecnologías han revolucionado el mundo escolar y cómo ellas están cambiando la forma de pensar y actuar de los agentes implicados en el proceso de enseñanza-aprendizaje, en una sociedad globalizada e informatizada. Se trata de un estudio descriptivo e hipotético, se realizará con base en una investigación bibliográfica e histórica, utilizando el método inductivo.

Educación Jurídica. Tecnología. Profesor. Enseñanza Jurídica. Nuevas Formas de Aprendizaje.

\section{La richiesta di nuovi standard nell'educazione giuridica di fronte alle nuove tecnologie}

\section{SOMMARIO}

Questo articolo si propone di affrontare le questioni relative alle risorse di apprendimento utilizzate nelle classi e all'inclusione di nuove tecnologie nell'educazione giuridica, come un'ulteriore opzione di strumento che può essere implementata nel processo di insegnamento e apprendimento. Ė importante verificare se c'è una comprensione da parte degli insegnanti di diritto delle reali tendenze per il futuro, se hanno un'idea degli impatti effettivi che le nuove tecnologie hanno rivoluzionato il mondo scolastico e di come stanno cambiando il modo di pensare e di agire gli agenti coinvolti nel processo di insegnamentoapprendimento, in una società globalizzata e informatizzata. Si tratta di uno studio descrittivo e ipotetico, sarà condotto sulla base di una ricerca bibliografica e storica, utilizzando il metodo induttivo.

Educazione giuridica. Tecnologia. Insegnante. Educazione legale. Nuovi modi di apprendimento.

\section{INTRODUÇÃO}

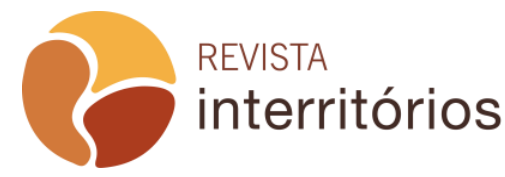


Os últimos anos têm sido marcados por mudanças educacionais com a predominância do uso de novas tecnologias cujo o objetivo é a construção do próprio conhecimento pelo aluno, capacitando ao professor auxiliar o desenvolvimento de uma nova capacidade até agora não imaginada no sentido da ampliação do intelecto humano.

Importante observar que a sociedade sempre esteve em constante transformação desde a revolução industrial. No entanto, o que se percebe é que, nos dias atuais, essas modificações diante do uso da tecnologia são, muitas vezes, instantâneas.

Nesse sentido, procurar-se-á verificar nesse estudo se a informação associada à robótica e a outras inovações tecnológicas de fundo, estão definitivamente encerrando a era industrial e inaugurando em novo tempo que se convencionou chamar de era pós-industrial.

O ser humano tem capacidade de armazenar informação e utilizá-las para o seu progresso e bem-estar. A tecnologia da sociedade de informação, por sua vez, amplia esta capacidade humana, bem além de qualquer nível julgado possível a um quarto de século, colocando conhecimentos à disposição dos que necessitam, quando e onde quer que estejam.

Desse modo, a protagonista no contexto da educação é a comunicação, a qual permite não só a transmissão de informações e conhecimentos, mas também a formação e desenvolvimento da personalidade do aluno, ou seja, a comunicação é o processo que permite a formação de valores, regras, capacidade e habilidades intelectuais e afetivas nos alunos.

Sendo assim e tendo em vista o uso de novas tecnologias no aprendizado, analisar-se-á em um primeiro momento questões pertinentes ao ensino jurídico no Brasil, a fim de tecer questionamentos relevantes, partindo-se da premissa que o processo de formação dos cursos de Direito no país, resultou na emancipação da cultura jurídica brasileira.

Por outro lado, diante da mudança de paradigma do ensino jurídico, aos poucos esse processo foi compelido a receber e se adaptar com as novas tendências tecnológicas. Deste modo, outro ponto importante que abordar-se-á, em um segundo momento, diz respeito as influências das tecnologias no ensino jurídico brasileiro, com intuito de observar se as atividades empregadas ao ensino jurídico precisam ser adequadas aos novos conceitos de mídias educacionais, de tecnologias de informação e comunicação e recursos digitais, legitimando assim uma nova modelação e mentalidade no universo acadêmico do Direito.

A atenção especial será dada a uma nova postura para o grande desafio educacional do futuro baseado na tecnologia, que representa um processo interativo centrado no aluno. Assim, para que isso aconteça entende-se ser

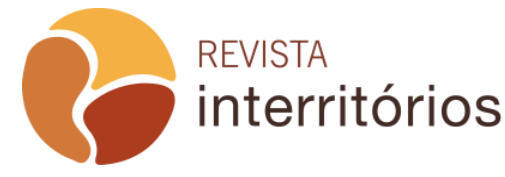


necessário que haja a mudança de todos os elementos básicos do processo: professor, aluno e conteúdo.

Ademais, o uso da tecnologia nas salas de aula provoca uma transformação na maneira de pensar dos docentes, uma vez que nos dias atuais não existem justificativas para a memorização mecânica de saberes seja de uma ou outra área, mas sim o desenvolvimento de competências que permitam ao aluno a capacidade de aprender sempre.

Por essa razão, examinar-se-á, por fim, o papel do professor frente aos avanços tecnológicos, uma vez que se buscará confirmar a história que os denominados nativos digitais não se encaixam nos métodos tradicionais de ensino, pois os alunos de hoje nasceram no ambiente da descoberta e da participação incrementado pelas novas ferramentas tecnológicas. Logo, constrói-se a hipótese que talvez seja necessário um novo modelo de aprendizagem, no qual a riqueza resida em novas formas de obter 0 conhecimento.

Frente às considerações acima e aos aspectos expostos nas linhas precedentes, o presente artigo tem por escopo abordar questões que dizem respeito aos recursos de ensino utilizados nas salas de aula e a inclusão das novas tecnologias no ensino jurídico, como mais uma possibilidade de ferramenta a ser implementada no processo ensino aprendizagem. Importante se faz, a compreensão pelos docentes de direito das reais tendências para o futuro e os efetivos impactos que as novas tecnologias podem ter no seu ofício e no mundo escolar, assim, como elas podem modificar o modo de pensar e agir das pessoas envolvidas no processo ensino-aprendizagem, numa sociedade globalizada e informatizada. Nesse sentido, fica evidente a justificativa e objetivos desse estudo.

Por se tratar de um estudo descritivo e exploratório, será realizado com base na pesquisa bibliográfica e histórica, utilizando-se por vezes do método indutivo.

\section{Ensino Jurídico no Brasil - Breve consideração histórica}

Nos séculos XVII e XVIII, destacado pelos ideais da Revolução Francesa, liberdade, igualdade e fraternidade, tem-se em 07 de setembro de 1822 a libertação do Brasil em relação à antiga metrópole, ocasião que é formado o Estado nacional brasileiro, e tem início o período do Brasil Imperial.

Apesar de tornar-se independente, no tocante a questão jurídica, a sociedade brasileira continuava a ser dependente de Portugal, uma vez que apenas alguns indivíduos que pertenciam a uma elite detentora do poder econômico podiam almejar a condição de bacharéis. Deste modo, o ensino

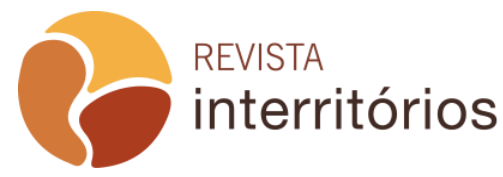


jurídico se apresentava preso ao que se estudava na Universidade metropolitana de Coimbra.

Assim sendo, algumas décadas antes do fim do Ainda sob o domínio português no Brasil, a Universidade de Coimbra sofreu uma modificação proporcionada pelo Marques de Pombal.

Bacharel em Direito formado na Universidade de Coimbra, Marques de Pombal queria modernizar o ensino com o propósito de abandonar as tradições medievais, aproximando, deste modo, a Universidade das demais escolas jurídicas europeias.

As alterações efetuadas por Marques de Pombal reformas no ensino jurídico em Coimbra, deu origem ao pensamento iluminista europeu, todavia com pífios e resultados com relação à aproximação do estudante de Direito à realidade colonial e social brasileira.

Em janeiro de 1808, com a invasão de Portugal pelas tropas napoleônicas, transfere-se para o Brasil toda a Corte Real Portuguesa. Diante de tal situação foram organizadas as questões administrativas oriundas de Lisboa, inclusive no setor cultural com a criação de várias instituições destinadas a dar continuidade às que existiam em Portugal.

Salienta Tércio Sampaio Ferraz Júnior (1994, p. 93) que com a chegada da corte portuguesa, no ano de 1808, tem início efetivo o ensino superior no Brasil, uma vez que se criaram as escolas de Cirurgia e Anatomia em Salvador, atual Faculdade de Medicina da Universidade Federal da Bahia; no Rio de Janeiro a criação da cadeira de anatomia no Hospital Militar e a Academia da Guarda Marinha.

Ocorrida a independência do Brasil em 1822, e a instauração da pioneira assembleia constituinte em 1823 foi criada uma comissão de instrução pública que apresentou um esboço do Patriarca José Bonifácio, considerado o pioneiro ministro da educação do Brasil de 16/01/1822 a 17/07/1823, para a organização das universidades do Brasil.

Contudo, com a convocação da primeira Assembléia Constituinte, objetivando a criação da primeira constituição brasileira, Visconde de São Leopoldo apresentou a indicação e a justificativa para a criação dos primeiros cursos jurídicos em território nacional.

Por decreto do governo imperial, foram criados em 11 de agosto de 1827, os primeiros cursos de Direito brasileiros, em São Paulo e em Olinda. As estruturas curriculares trazidas no corpo da lei que, em agosto de 1827, criou os primeiros cursos jurídicos no país, foram posteriormente alteradas e adaptadas por meio de vários outros decretos.

Portanto, o processo de elaboração dos cursos de Direito no país, resultou na emancipação da cultura jurídica brasileira. Com forte influência do 
Liberalismo-individualista da época, os primeiros cursos de Direito difundiram esse pensamento na forma de ideologia político-jurídica na sociedade brasileira.

No velho convento, datado do início do século XVI, instalou-se no Largo de São Francisco a Academia de Direito. Em 1825, a biblioteca já contava comum bom acervo, reunido de longa data pelos frades franciscanos e tornouse a primeira biblioteca pública de São Paulo, antes mesmo da inauguração da Faculdade.

Observa-se que os principais movimentos políticos da História do Brasil, iniciaram com a Academia de Direito de São Paulo desde o Abolicionismo de Joaquim Nabuco, Pimenta Bueno e Perdigão Malheiro e do Movimento Republicano de Prudente de Moraes, Campos Salles e Bernardino de Campos até a campanha das Diretas Já.

Por sua vez, a Faculdade de Direito do Recife foi instalada em Olinda, no ano de 1828, mas surgiu, de fato, em 1854, após a transferência da Faculdade de Direito de Olinda para a capital da província de Pernambuco. No ano de 1912, mudou-se para o prédio onde funciona até hoje, no Recife.

Nos anos de 1860 a 1880 na Faculdade de Direito do Recife surgiu o movimento intelectual poético, crítico, filosófico, sociológico, folclórico e jurídico conhecido como a Escola do Recife, liderado por Tobias Barreto de Meneses. Esse período trouxe alterações decisivas para o ensino jurídico e para a própria educação brasileira.

O Decreto 7247 , promulgado em 19 de abril de 1879, que implantou no Brasil a liberdade de ensino e, consequentemente, ocorreu uma reestruturação do currículo e organização das Faculdades de Direito. Os debates acerca da constitucionalidade ou não deste decreto culminaram com a elaboração de um projeto da Comissão de Instrução Pública, de nㅜ 64, tendo como relator o jurista brasileiro, Ruy Barbosa.

Ruy Barbosa redigiu os seus Pareceres/Projetos sobre educação apresentando a educação como uma questão de vida ou morte para o país, buscando com a reforma, queria reorganizar totalmente o programa escolar brasileiro, adaptando-o à nova realidade mundial. Sugeria na sequência mudanças de programas e métodos de ensino e o fim do ensino religioso vez que se discutia a necessidade de separação entre o Estado e a Igreja. Assim, deveria o ensino ser laico, gratuito e obrigatório.

Concluindo-se a fase imperial destacada pela criação e consolidação de cursos jurídicos com a presença marcante da figura do bacharel em Direito, mudou-se o cenário com a Proclamação da República brasileira, período inovador para educação do pais com a criação de faculdades livres.

Evidenciando, finalmente o rompimento intelectual com a Igreja por parte do Estado, por meio do Decreto ํㅜㄴ 1036A, em 14 de novembro de 1890 é abolida 
a disciplina de Direito Eclesiástico dos Cursos Jurídicos da Faculdade de Olinda e da Faculdade de Direito de São Paulo. Nota-se que a Constituição Republicana de 1891, no capítulo dedicado à educação, admitia no art. 34 que ao Congresso incumbiria criar instituições de ensino superior.

Durante o mandato do $3^{\circ}$ presidente da República, o advogado Prudente de Moraes, em 1896, passa a vigorar o Decreto n- 2.226 que aprovou o Estatuto das Faculdades de Direito e institui várias disposições sobre o modelo a ser adotado pelas Faculdades.

Com o passar dos anos, mais precisamente após 1900 começaram a ser estruturados em Minas Gerais, Rio de Janeiro, Bahia, Ceará e Rio Grande do Sul novos cursos de Direito.

Após o advento do Estado Moderno e o modelo de cientificismo positivista previsto em nosso país, converteu-se o conhecimento jurídico por meios dos manuais de Direito e livros, o que ocasionou um processo de crise no que diz respeito a legitimidade, elaboração e aplicação da justiça, uma vez que a formação do profissional na área jurídica consiste em ler e decorar leis, artigos, parágrafos, incisos e alíneas.

Segundo Vladmir Oliveira da Silveira e Samyra Haydêe Sanches:

[...] O Ensino Jurídico apresenta sérios problemas desde seus primórdios, uma vez que a situação verificada nos tempos do Brasil Colônia, quando as famílias enviavam seus filhos a Portugal para buscar a formação jurídica que não encontravam aqui, pouco se modificou. Das Ordenações Alfonsinas e Manoelinas para o Código Civil de 1917, do Penal de 1940 ao Código de Defesa do Consumidor de 1990, a formação do profissional na área jurídica consiste predominantemente em ler e decorar leis, artigos, parágrafos, incisos e alíneas. (SILVEIRA; SANCHES, 2013. p. 497).

Em suma, o ensino jurídico brasileiro com fulcro no positivismo jurídico encontra-se diante da modernidade trazida pelas tecnologias, completamente em crise, uma vez que a metodologia de ensino e aprendizado voltados na repetição e leitura dos manuais, ocasionam total desestímulos aos alunos.

Deste modo, a preocupação passa a ser voltada ao desenvolvimento de ambientes de aprendizagem com o uso da tecnologia empregada, com o uso real dos conceitos de interatividade entre os alunos e professores, e não apenas o uso puro e simples de equipamentos novos e modernos voltados para memorização de leis, no qual a troca e a aprendizagem sejam um todo contínuo e intercambiável.

\section{As influências das Tecnologias no Ensino Jurídico Brasileiro}

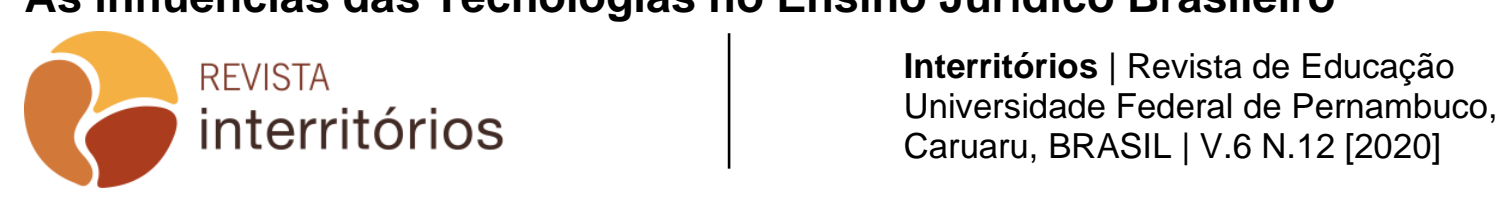


Decorrente da denominada revolução tecnológica, ocorridas no século $\mathrm{XX}$, o mundo começa a se deparar com uma forte transformação baseada pelo aumento e velocidade das informações, o que ocasionou novas possibilidades tecnológicas em todos os setores da sociedade, ou seja, no setor econômico, cultural e educacional.

O uso de computadores, no âmbito da educação, rompeu os limites, por meio da multimídia. Há alguns anos íamos a uma biblioteca, exclusivamente para ler um livro. Hoje os frequentadores não só lêem, como vêem as imagens e ouvem os sons nas suas pesquisas em sala de aula e nas bibliotecas. Evidente que não se tem a multimídia em todas as escolas, mas é provável que daqui a pouquíssimo tempo os alunos a terão e os docentes deverão estar aptos a lhes mostrar este mundo e recursos e a deixar que o explorem².

Sobressaindo esse cenário os alunos passam a ocupar uma posição muito inusitada, pois ao mesmo tempo que sofrem a influência do avanço da tecnologia, da comunicação e dos costumes, são também eles que provocam os docentes para mudança, uma vez que os professores, assistem a incrível capacidade de assimilação dos alunos, no que diz respeito ao uso dos computadores e smartphones.

Diante das constantes transformações nada mais oportuno que um momento de reflexão no caminhar do ensino jurídico com intuito de se estabelecer uma possível revisão a sua estrutura. Desse modo, surge a preocupação que as atividades empregadas ao ensino jurídico devam ser adequadas aos novos conceitos de mídias educacionais, de tecnologias de informação e comunicação e recursos digitais, legitimando assim uma nova modelação e mentalidade no universo acadêmico do Direito. A referida reflexão iniciou-se na década de 1990, com a ampliação da internet como grande ferramenta de difusão de informação.

Nesse sentido Ruschel e Rover afirmam que:

O Direito permeia hoje todos os ramos de atividades da sociedade, inclusive a internet, e em nível mundial. $O$ uso das inovadoras ferramentas da internet ajuda, por serem um meio, a atingir o objetivo do aprendizado mediado pelo computador e tutoriado pelo professor. (RUSCHEL; ROVER, 2009, p. 4).

\footnotetext{
2 Segundo Moran, Masetto e Behrens contemporaneamente o reconhecimento da "era digital" como nova forma de categorizar o conhecimento não implica descartar todo o caminho trilhados pelas linguagens oral e escrita, nem mistificar o uso indiscriminado de computadores no ensino, mas enfrentar com critérios os recursos eletrônicos como ferramentas para construir processos metodológicos mais significativos para aprender..
}

\begin{tabular}{l|l} 
REVISTA & Interritórios | Revista de Educação \\
interritórios & $\begin{array}{l}\text { Universidade Federal de Pernambuco, } \\
\text { Caruaru, BRASIL | V.6 N.12 [2020] }\end{array}$
\end{tabular}


Corroborando com esse entendimento Vladmir Oliveira da Silveira e Samyra Haydêe Sanches salienta que:

Há ainda a questão do conhecimento jurídico disponibilizado pela internet. Esta poderia ser mais utilizada e mais bem aproveitada como ferramenta didática para, por exemplo, a pesquisa de casos e julgados que enriqueceriam sobremaneira as matérias lecionadas em sala de aula, permitindo também o acesso a obras e periódicos internacionais. Para tanto, é necessária a criação de sítios confiáveis, em que os artigos passem por crivos de cientificidade. Destarte, os periódicos eletrônicos, devidamente avaliados e classificados pelos órgãos competentes, poderiam representar uma ferramenta fundamental para a difusão de pesquisas e o estímulo ao debate, o que infelizmente ainda é raro na área jurídica. (SILVEIRA; SANCHES, 2013, p. 510).

Em uma velocidade nunca antes presenciada, a tecnologia se apresenta como mecanismo de ampliação e transformação de formas de interação entre os indivíduos, colocando ao docente o desafio de como associar essa nova forma de pensar, incitada pelo universo cibernético, ao desenvolvimento de conhecimento do seu aluno.

Diante desta mudança de paradigma, o ensino jurídico aos poucos foi compelido a receber e se adaptar às tendências tecnológicas, uma vez que as forma relacionadas a maneira de se pesquisar, por exemplo, a jurisprudência, dantes extremamente complexas e penosas, realizadas em bibliotecas e em livros de papel, passaram a ser desenvolvidas na velocidade dos cliques do mouse. Diante desse contexto Eduardo Cassela (2009) acrescenta, ainda, que:

Chegará o dia em que não será necessário deslocarmos de casa ou do trabalho para obter uma certidão, requerer uma autorização, fazer uma comunicação de delito. O acesso ao governo será on-line, em tempo real, tanto o que se procura como a resposta que buscamos, através de um crescimento contínuo, gradual e sem interrupção dos sistemas informatizados oficiais. (CASSELA, 2009, p. 58-59).

Ademais, aqueles que realizavam seus estudos comparando a legislação dos mais diversos Estados-membros também apreciavam na internet e no computador a agilidade e a facilidade de não mais precisar esperar meses por um código ou uma lei editada em papel.

Evidencia-se, diante de tais implicações, a importância de se abordar as ferramentas tecnológicas para o ensino superior, especialmente, nos cursos jurídicos com intuito de que seja possível identificar as reais lacunas do ensino, frente a esta revolução no final desta década, que está sendo o processo 
eletrônico e os meios probatórios os sustentáculos do direito no novo século, com uma atividade mais próxima dos recursos e menos dogmáticos.

$\mathrm{Na}$ história de progressão ao sistema de educação não houve nada semelhante a revolução tecnológica presenciada atualmente, pois as ferramentas que surgiram ao longo dos anos como retroprojetores, mimeógrafos, apresentadores de slides, não podem ser considerados frente às Tecnologias da Informação e Comunicação (TIC's). O que muitas vezes nos causa espanto é a velocidade desta mudança algo que no período daquelas revoluções educacionais não foram fatores determinantes para um rompimento do paradigma outrora existente.

Atento a essas mudanças de paradigmas, bem como ao significativo acréscimo que estava trazendo para o ensino no Brasil, foi inserida na Lei 9.394/96 - Lei de Diretrizes e Bases da Educação Nacional, em seu artigo 80, prevê a seguinte disposição: "O Poder Público incentivará o desenvolvimento e a veiculação de programas de ensino a distância, em todos os níveis e modalidades de ensino, e de educação continuada.", posteriormente regulamentado pelo Decreto 5.622/2005.

O Ministério da Educação buscou regulamentar o uso da educação não presencial pelas instituições de ensino superior, e ainda, no intento de padronizar as regras para fiscalização da qualidade de ensino, editou a Portaria no 40/2007.

A possibilidade do ensino à distância - EaD como nova modalidade ou como uma ferramenta de auxílio ao ensino presencial fez com que muitas pessoas que estavam afastadas do meio acadêmico retornassem a estes ambientes com motivação extra, a maior interatividade e dinâmica na aprendizagem. Neste contexto, os alunos estão diante de novas ferramentas desenvolvidas por intermédio da internet para o ensino à distância como os Ambientes Virtuais de Aprendizagem - AVA.

Hoje o ensino à distância - EaD está sendo implementado em muitos cursos presenciais como maneira de promover a inteligência coletiva, ampliar as possibilidades de interatividade no sistema de ensino. A adoção das Tecnologias da Informação e Comunicação não é mais vista pelos alunos como algo em desconformidade com o ensino presencial, mas sim como um enriquecimento da aprendizagem, uma forma mais agradável de exercerem sua corresponsabilização no ensino. Todavia, o curso de direito ainda não se autorizou o curso cem por cento em Ensino à Distância.

A ferramenta de $\mathrm{EaD}$ com maior alcance é a plataforma Moodle que significa Ambiente de Aprendizagem Modular orientado ao objeto dinâmico (Modular Object-Oriented Dynamic Learning Environment), uma das mais utilizadas ferramentas de suporte ao EaD em 155 países e com mais de $54 \%$ do mercado internacional, alcançando 4 milhões de alunos em 360 mil cursos. Só 
no Brasil o sistema depois da implantação pela Universidade Aberta do Brasil é usado por mais de 200.000 alunos (SABBATINI, 2007).

Corroborando para o entendimento, Renato Sabbatini acrescenta que:

O Moodle é também um sistema de gestão do ensino e aprendizagem (conhecidos por suas siglas em inglês, LMS Learning Management System, ou CMS - Course Management System), ou seja, é um aplicativo desenvolvido para ajudar os educadores a criar cursos on-line, ou suporte on-line a cursos presenciais, de alta qualidade e com muitos tipos de recursos disponíveis. (SABBATINI, 2007, p. 1).

A plataforma moodle foi introduzida no ensino presencial com a inserção de disciplinas semipresenciais pela Portaria MEC $n . .04 .059 / 2004$, que estabelece em seu artigo $1^{\circ}$, parágrafo segundo que: "Poderão ser ofertadas as disciplinas referidas no caput, integral ou parcialmente, desde que esta oferta não ultrapasse $20 \%$ (vinte por cento) da carga horária total do curso." A partir desta permissão normativa, os cursos passaram a sistematicamente utilizar-se da tecnologia para afastar-se da já referida educação bancária. Importante ressaltar que a oferta dos referidos $20 \%$ só é passível em cursos reconhecidos pelo Ministério da Educação - MEC.

No que diz respeito a plataforma moodle destaca Oliveira e Fireman (2008) que:

O Moodle permite que estes mecanismos sejam oferecidos ao aluno de forma flexibilizada, ou seja, a grande responsabilidade para a elaboração dos materiais e definição das atividades destinada aos alunos, individualmente ou em grupo, é do professor, que além de produtor de materiais e de atividades, deve buscar situações as quais incentivem a autonomia, a criatividade, a cooperação e a colaboração entre os pares, além de poder definir a sua disposição na interface, poderá utilizar metáforas que imputem a estas ferramentas diferentes perspectivas, que apesar de utilizarem a mesma funcionalidade, se tornem espaços didáticos únicos. (OLIVEIRA; FIREMAN, 2008, p. 8).

Deste modo, o referido mecanismo traz inovações no sentido de propiciar situações as quais incentivem a autonomia, a criatividade, a cooperação e a colaboração entre os alunos e professores. No entanto, observa-se que, ainda que uma pequena parcela, as universidades brasileiras têm investido nesta integração, sobretudo na instalação de infraestrutura física, a exemplo, das 
redes wireless ${ }^{3}$, backbones ${ }^{4}$ e roteadores ${ }^{5}$. Nesse processo, o campus universitário se transforma se interconecta e se ramifica além de sua demarcação física.

Importante ressaltar que o processo de implementação do uso da tecnologia na sala de aula com intuito de aprimorar o aprendizado atendendo as atividades jurídicas especificas e aos seus aspectos de interesses sociais é um desafio, uma vez que significa uma mudança na atitude e na metodologia do professor consciente sobre os inevitáveis reflexos que, evidentemente, afetaram sua prática pedagógica e o processo de construção de conhecimentos de seus alunos.

\section{O Papel do Professor frente aos Avanços Tecnológicos}

A utilização das tecnologias da informação e comunicação nas salas de aula instiga os professores a repensarem a construção do ensino e aprendizado. A ideia traduz a prioridade para o desenvolvimento da autonomia intelectual e do pensamento crítico com o uso das tecnologias desenvolvidas em cada uma das áreas.

A inserção da tecnologia se fundamenta na perspectiva de um recurso educativo, não apenas para o domínio da máquina e sua linguagem, mas sim para sua utilização na busca de maior entendimento do mundo real que cerca a pessoa humana.

Desse modo, as tecnologias são entendidas como integrantes transversais para todas as áreas do conhecimento, permitindo acesso às diferentes dinâmicas que oferecem possibilidades e limites como alicerces para o aprendizado.

\footnotetext{
${ }^{3}$ Uma rede sem fio refere-se a uma rede de computadores sem a necessidade do uso de cabos - sejam eles telefônicos, coaxiais ou ópticos - por meio de equipamentos que usam radiofrequência (comunicação via ondas de rádio) ou comunicação via infravermelho. É conhecido também como wireless.

4 No contexto de redes de computadores, o backbone (backbone traduzindo para português, espinha dorsal, embora no contexto de redes, backbone signifique rede de transporte) designa o esquema de ligações centrais de um sistema mais amplo, tipicamente de elevado desempenho. Por exemplo, os operadores de telecomunicações mantêm sistemas internos de elevadíssimo desempenho para comutar os diferentes tipos e fluxos de dados (voz, imagem, texto, etc). Na Internet, numa rede de escala planetária, podem-se encontrar, hierarquicamente divididos, vários backbones: os de ligação intercontinental, que derivam nos backbones internacionais, que por sua vez derivam nos backbones nacionais.

5 Roteador (estrangeirismo do inglês router, ou encaminhador) é um equipamento usado para fazer a comutação de protocolos, a comunicação entre diferentes redes de computadores provendo a comunicação entre computadores distantes entre si. A principal característica desses equipamentos é selecionar a rota mais apropriada para encaminhar os pacotes recebidos. Ou seja, escolher o melhor caminho disponível na rede para um determinado destino.
} 
Nesse sentido, o uso da tecnologia nas salas de aula provoca uma transformação na maneira de pensar dos professores, uma vez que nos dias atuais não existem justificativas para a memorização mecânica de saberes seja de uma ou outra área, mas sim o desenvolvimento de competências que permitam ao aluno a capacidade de aprender sempre.

Importante ressaltar que, o aprendizado jurídico está para além do mero estudo do texto de lei, uma vez que se apresenta como um sistema muito mais dinâmico, possibilitando tanto a revisão das categorias normativas quanto a consideração do estudo como integrante de um processo internacional, social, histórico e político diante das transformações de atuais ${ }^{6}$.

Os denominados nativos digitais não se encaixam nos métodos tradicionais de ensino, pois os alunos de hoje nasceram no ambiente da descoberta e da participação incrementado pelas novas ferramentas tecnológicas. Logo, faz-se necessário um novo modelo de aprendizagem, no qual a riqueza reside em novas formas de obter o conhecimento.

A questão que precisa ficar clara é que a tecnologia empregada na sala de aula não tem como pretensão a substituição do professor, mas, sim exigir que o mesmo tenha um preparo diferenciado e atualizado, sendo elemento fundamental para preparar o material didático no formato oferecido, como suporte no processo de aprendizagem do aluno e como avaliador do processo de aprendizado.

O que se pretende é a busca de novas capacidades tecnológicas por parte do professor no que tange o preparo do material. Evidentemente que o tempo dedicado a esse processo pode ser maior, uma vez que há um aproveitamento melhor pelo uso dos recursos tecnológicos e uma renovação do material com maior frequência.

Corroborando com esse entendimento, esclarece Fantin:

\begin{abstract}
Pensar a educação como ação em busca designificação implica perceber o papel da mediação na relação entre sujeito e cultura no sentido de ampliar o conhecimento de $\mathrm{si}$, do outro e do mundo, possibilitando tal entendimento como interações e experiências que os sujeitos constroem participando dos sistemas simbólicos da cultura. Para além da informação e da imagem, a comunicação e suas tecnologias têm apresentado outros modos de inteligibilidade do mundo. (FANTIN, 2008, p. 2).
\end{abstract}

\footnotetext{
${ }^{6}$ SILVEIRA. Vladmir Oliveira da; SANCHES. Samyra Haydêe Dal Farra Naspolini. $A$ Reprodução do Paradigma Dogmático da Ciência do Direito no Ensino Jurídico e a Necessidade de Mudanças na Pesquisa Jurídica, que Permitam uma Efetiva Educação Jurídica. In: Educação Jurídica. Ed. Saraiva. 2013. p. 500.
} 
O emprego da tecnologia na sala de aula está atrelado ao que se espera do processo de aprendizagem, ao modo do professor e ao conteúdo considerado. Assim, quando o indivíduo opta pela formação universitária jurídica variantes, no que tange ao desenvolvimento cognitivo e o crescimento dos aspectos cultural e social são essenciais de serem abordados pelo professor.

Ademais Laymert Santos assegura que:

\begin{abstract}
Desde as revoluções científica e industrial, que ocorreram na Europa, a tecnologia tem sido alçada de sua condição de meio para preencher necessidades humanas à de finalidade e objetivo da aspiração humana. Tal mudança também significou que a transformação tecnológica deixou de ser considerada e avaliada com base em valores humanos; ao contrário, a existência humana passou a ser considerada segundo o padrão da rápida mudança tecnológica. Já não se perguntava mais quais seriam os impactos sociais, culturais e ecológicos da introdução em larga escala de uma tecnologia específica, se ela era desejável ou imprópria. A tecnologia não precisava ser mais adaptada à sociedade e à natureza; passou-se a esperar que a sociedade e a natureza se adaptassem à tecnologia; e para essa adaptação impositiva e violenta, nenhum custo social e ecológico foi considerado excessivo. (SANTOS, 2003, p. 74).
\end{abstract}

Diante do novo contexto de aprendizagem, com uso da tecnologia na sala de aula, o professor não será apenas um transmissor conforme convencionouse no ensino tradicional. Ele deverá estar apto a atender as necessidades individuais dos alunos. E nesse sentido, a interação digital possibilita uma nova visão da educação e, de modo mais abrangente, do aprendizado.

A preocupação passa a ser voltada ao desenvolvimento de ambientes de aprendizagem com 0 uso da tecnologia empregada, com 0 uso real dos conceitos de interatividade entre os alunos e professores, e não apenas o uso puro e simples de equipamentos novos e modernos, no qual a troca e a aprendizagem sejam um todo contínuo e intercambiável. Logo a proposta é que o processo de conhecimento transmitido seja alterado para o aprendizado interativo.

Segundo Pierre Levy (1999) o profissional competente deve não apenas saber manipular as ferramentas tecnológicas, mas incluir sempre em suas reflexões e ações didáticas a consciência de seu papel em uma sociedade tecnológica.

Os nativos digitais têm uma capacidade já incorporada de fazer várias tarefas simultaneamente, de circular por vários ambientes virtuais em busca de informações e subsídios de vários formatos, pois eles são incrivelmente habilidosos ao lidar com diversos meios de informação. São capazes de

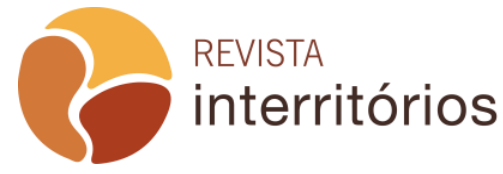


realizarem várias atividades ao mesmo tempo, lideram a corrida pela informação de forma inovadora.

Assim, o papel do professor como estruturador e organizador do aprendizado deve ser revisto, para ter como base o aluno. A antiga prática educativa onde parte significativa da aula é marcada pelo processo professor fala e aluno escuta deve evoluir para o reconhecimento das habilidades, contextos, culturas e outros fatores formadores do aprendizado, uma vez que as informações já estão disponíveis pelas páginas da internet.

Reforçando a ideia do novo papel do professor salienta Araci Hack:

O processo educacional docente é desafiado cotidianamente devido à introdução de mídias e multimídias na educação. Novas habilidades são requeridas do professor atualmente e uma experiência prática de produção audiovisual pode ser elucidativa, pois além de abrir a perspectiva de leituras multidisciplinares sobre a temática, trará a possibilidade de experimentar a roteirização e realização de peças educativas com alunos e professores voluntários. Por isso, é importante a projeção de outros estudos que aprofundem os fundamentos de uma produção audiovisual educativa que vá além da tele-aula, ou seja, um produto que possa ser admirado por sua qualidade artística, como as obras cinematográficas. (CATAPAN, 2008, p. 8).

Torna-se um desafio, tanto para professores, quanto para instituições de ensino superior a possibilidade de uma mudança educacional. No tocante as instituições as mesmas almejam quanto ao interesse de seu futuro público alvo, abertura à criatividade, possibilidade de colaboração interdisciplinar e independência de decisões combinadas com a incerteza quanto aos futuros resultados que dependerão de seu entusiasmo e de seu conhecimento sobre a nova tecnologia.

Neste caso, a estratégia de implementação do uso da tecnologia na sala de aula deve ser a de, num primeiro momento, apresentar e desenvolver atividades informativas e formativas, práticas e teóricas que proporcionem familiaridade e confiança com e sobre o sistema computacional.

Determinadas atividades devem ser conduzidas visando dar um respaldo técnico e tecnológico aos professores para que a partir de aí se sentirem aptos para a participação e debates que os conduzam à suas próprias decisões quanto ao uso lúdico e criativo do computador e à escolha dos softwares adequados aos seus objetivos estabelecidos.

Nesse sentido, o que se propõe é ao final deste processo de capacitação e formação do professor quanto ao uso das ferramentas tecnológicas em suas atividades em sala de aula, é que cada professor encontre a sua própria 
estratégia quanto ao melhor uso desta ferramenta de trabalho, desenvolvendo um diferente planejamento didático e metodológico com seus alunos.

Assim, com o aprendizado de uma nova ferramenta de trabalho unida com todo nosso conhecimento jurídico pode-se exercitar novas formas de aprendizado por meio dos programas de computador, tendo em vista que com a multimídia a pesquisa dos assuntos é facilitada e acrescida de som e movimento, o qual estimula o aluno a fazer a relação de seu aprendizado com o seu futuro trabalho, tornando-o um ser consciente.

O interessante seria agregar a contribuição deste aprendizado a maneira que futuramente ele exercerá sua profissão de modo que o torne apto a enfrentar um mercado de trabalho competitivo ao extremo.

Aprender e assimilar o conhecimento produzido pela humanidade e os novos paradigmas, são imprescindíveis para entender as exigências do mercado competitivo do trabalho, para tanto necessário se faz adaptar-se a esta nova era tecnológica e integrar-se a ela, sabendo lidar com a realidade imposta pelo mundo virtual.

Corroborando com esse entendimento Moran afirma que:

Nosso desafio maior é caminhar para um ensino e uma educação de qualidade, que integre todas as dimensões do ser humano. Para isso precisamos de pessoas que façam essa integração em si mesmas no que concerne aos aspectos sensorial, intelectual, emocional, ético e tecnológico, que transmitem de uma forma fácil, entre o pessoal e o social, que expressem nas suas palavras e ações que estão sempre evoluindo, mudando, avançando. (MORAN, 2004, p. 15).

Portanto, conclui-se que professores devem antes aprender conjuntamente com seus alunos, de forma qualitativa e não autoritária, desfrutando de métodos eficazes de aprendizagem por meio do uso da tecnologia.

Deverão ser os facilitadores em um processo de ensino aprendizagem, e não podem oferecer as respostas para todas as perguntas tendo em vista que são sujeitos dos saberes e mediadores de toda atividade desenvolvida na sala de aula, razão pela qual necessitam apropriarem-se das novas tecnologias, não apenas com a intenção de motivar os alunos, mas para compreender o processo ativo e dinâmico que ocorre nessa interação entre o aprendizado e a tecnologia.

\section{CONCLUSÃO}


O uso da tecnologia na sala de aula é utilizado como uma ferramenta para apoiar a indagação, composição, colaboração e comunicação dos alunos, uma vez que o aluno não mais aceita o professor dono da verdade, o mesmo é capaz de procurar, refletir e criticar as informações que lhes estão sendo oferecidas ocasião em que o mesmo constrói seu próprio conhecimento.

Com isso, o professor, nesse momento, deixa de ser o centro do processo ensino aprendizagem, mas continua sendo fundamental para construir com os alunos seus próprios conhecimentos, logo deverá adotar o uso da tecnologia como um meio para novos fins, para uma aprendizagem mais dinâmica.

A intenção é fazer o uso da tecnologia com abordagens construtivistas de ensino, que enfatizam mais a solução de problemas, o desenvolvimento de conceitos e o raciocínio crítico do que a simples aquisição de conhecimento dos fatos.

Desse modo, sala de aula tornar-se um ambiente de aprendizagem cooperativa, na qual o professor fornece a direção, a orientação e a inspiração tornando-se mais interessante na medida em que com o auxílio de poderosas ferramentas de ensino vai despertando a curiosidade no aluno pelo conhecimento.

Sem dúvida que as tecnologias na sala de aula são ferramentas que foram desenvolvidas para melhorar a qualidade de ensino e ajudar os professores a fazer uso de uma variedade de estilos de aprendizagem, bem como ampliar o acesso de informações e possibilidades dado aos estudantes na sala de aula.

Nesse sentido, tanto o professor quanto a instituição de ensino devem inserir disciplinas, metodologias de análise e de comparação das características dos suportes midiáticos em termos de estrutura, linguagem e capacidade de armazenar, difundir e compartilhar informações para que possam desfrutar nas novas tecnologias.

Interessante ressaltar que o aluno, por sua vez, tem de fazer suas próprias mudanças de paradigmas concernentes ao uso dessas novas tecnologias, pois, o mesmo passa a ser o responsável pela aquisição e produção do seu próprio conhecimento. $O$ estudante passa a ser o protagonista ao invés de simples assistente ou expectador. Ele se confronta, se desafia.

O novo papel do professor é o de ser um mediador, uma ponte entre a informação e o entendimento; e, a partir dessa relação, um estimulador de curiosidades e fonte de dicas para que o aluno viaje sozinho no conhecimento, obtido nos livros e nas redes de computador. A informação apresenta-se em proporção imersa, mas de nada adiante com escassez de entendimento.

Portanto, os avanços tecnológicos no ensino e seus efeitos são de extrema relevância para o futuro do aprendizado e, em especial no ensino do direito, na qual a retórica ortodoxa, ainda reina de forma soberana, mas que vai 
sendo aos poucos auxiliada pelo suporte importante das tecnologias da informação e comunicação.

Por fim, no atual contexto de avanço tecnológico e intenso fluxo de informação, coloca-se para a educação o pensar em novos padrões sobre a relação humana com os processos de formação num ambiente virtual criado pelo homem.

\section{REFERÊNCIAS}

BERNARDES, Marciele Berger; ROVER, Aires José. Uso das novas tecnologias de informação e comunicação como ferramentas de modernização do ensino jurídico. Disponível em:

http://www.buscalegis.ccj.ufsc.br/revistas/index.php/observatoriodoegov/article/viewFil e/33640/32738. Acesso em: 22 fev 2019.

BRASIL. Lei no 9.394, de 20 de dezembro de 1996. Disponível em: http://www.planalto.gov.br/ccivil_03/leis/L9394.htm. Acesso em 3 de março de 2019.

BRASIL. Ministério da Educação. Portaria no 4.059, de 10 de dezembro de 2004. Disponível em: http://portal.mec.gov.br/sesu/arquivos/pdf/nova/acs_portaria4059.pdf. Acesso em: 03 mar 2019.

BRASIL. Decreto no 5.622, de 19 de dezembro de 2005. Disponível em: http://www.planalto.gov.br/ccivil_03/_Ato2004-2006/2005/Decreto/D5622.htm. Acesso em: 03 mar 2019.

BRITO, Gláucia da Silva; PURIFICAÇÃO, Ivonélia da. Educação e novas tecnologias: um (re)pensar. 3. ed. Rev. atual. e ampl. Curitiba: IBPEX, 2011.

CASSELA, Eduardo Marcelo. Governo Eletrônico (Governo on-line) - Aspectos de Viabilização e Otimização dos Serviços Públicos. BuscaLegis.ccj.ufsc.br. Disponível em: http://www.buscalegis.ufsc.br/revistas/files/anexos/3679-3673-1PB.htm. Acesso em: 10 fev 2019.

CATAPAN, Araci Hack. O conhecimento escolar e o computador. Perspectiva. Florianópolis. v. 24, p. 173-181. Julho-dezembro, 1995.

FANTIN, Monica. Produção cultural para crianças e o cinema na escola. Anais da 26aㅗ Reunião Anual da ANPED, Poços de Caldas, 2008.

FERRAZ JÚNIOR, T. S. Introdução ao Estudo do Direito: Técnica, Decisão e Dominação. São Paulo: Atlas, 1994.

GABRICH, Frederico de Andrade; MENDONÇA, Rômulo Augusto Lasmar. Análise estratégica do ensino jurídico no Século XXI. Disponível em:

http://www.publicadireito.com.br/conpedi/manaus/arquivos/Anais/sao_paulo/2046.pdf. Acesso em: 16 fev 2019.

GRECO, Leonardo. O Ensino Jurídico no Brasil. Disponível em:

http://www.mundojuridico.adv.br/sis_artigos/artigos. Acesso em 16 fev 2019.

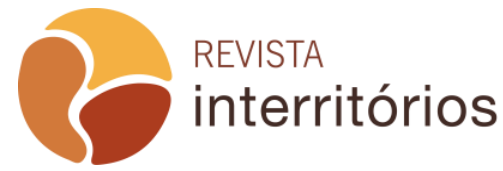


HOESCHL, Hugo Cesar (Org). Tecnologia da informação jurídica. Disponível em: http://www.i3g.org.br/editora/livros/tecnologiadainformacaojuridica.pdf. Acesso em: 01 mar 2019.

LEVY, Pierre. As tecnologias da inteligência: o futuro do pensamento na era da informática. Rio de Janeiro: Ed. 34, 1993.

LEVY, Pierre. Cibercultura. Tradução de Carlos Irineu da Costa. São Paulo: Editora 34, 1999.

LITTO, Fredric Michael .Um modelo para prioridades educacionais numa sociedade de informação. In: Pátio - Revista Pedagógica, Ano I, n.3, p.15-21, nov.97/jan98.

LOPES, José Reinaldo de Lima. 0 direito na história: lições introdutórias. São Paulo: Max Limonad. Morin, Edgar. Os sete Saberes Necessários à Educação do Futuro. 3a. ed. - São Paulo - Cortez; Brasília, DF: UNESCO, 2001.

MEDEIROS, Lucília A. O que é tecnologia. São Paulo, 1993.

MORAN, José Manuel. Internet no ensino. Comunicação \& Educação. V (14): janeiro/abril, 1999.

MORAN, José Manuel. A integração das tecnologias na educação. Artigo publicado na revista Informática na Educação: Teoria \& Prática. Porto Alegre, vol. 3, n.1 UFRGS. Programa de Pós-Graduação em Informática na Educação, p. 137-144.

MORAN, José Manuel. Ciência da Informação: como utilizar a Internet na educação. Disponível em: http//www.scielo.br/prof. Moran. Acesso em: 07 mar 2019.

MORAN, José Manuel; MASSETO, Marcos T; BEHRENS, Marilda Aparecida. Novas Tecnologias e mediação pedagógicas. 17.ed. São Paulo: Papirus. 2010.

NEGROPONTE, Nicholas. A Vida Digital. São Paulo: Companhia das Letras, 1995.

NISKIER, Arnaldo. A Educação na Virada do Século. Ed. Expressão e Cultura, Rio de Janeiro, $1^{\underline{a}}$ ed., 2001.

OLIVEIRA, Carloney Alves de; FIREMAN, Elton Casado. Ambiente Moodle como apoio ao Curso de Especialização em Gestão Escolar da Escola de Gestores/UFAL In: 2o Simpósio Hipertexto e Tecnologias da Educação, multumodalidade e ensino, 2008. Recife.

PRAKKEN, H. and SARTOR, G. A Dialectical Model of Assessing Conflicting Arguments in Legal Reasoning. Artificial Intelligence and Law. v. 4, n. 3-4, 1996.

RUSCHEL, Aírton José; ROVER, Aires José. O uso das tecnologias web no ensino do direito: a experiência da disciplina Informática Jurídica. Disponível em: http://www.scribd.com/doc/22518959/Artigo-O-uso-das-tecnologias-web-no-ensinonodireito-a-experiencia-da-disciplina-Informatica-Juridica. Acesso em: 22 fev 2019.

SABBATINI, Renato. Ambiente de Ensino e Aprendizagem via internet: a plataforma moodle. Disponível em: 
http://www.ead.edumed.org.br/file.php/1/PlataformaMoodle.pdf. Acesso em: 10 mar 2019.

SANTOS, Laymert Garcia dos. Limites e rupturas na esfera da informação. In:

Politizar as novas tecnologias: o impacto sociotécnico da informação digital e genética. Rio de Janeiro: Editora 34, 2003.

SILVEIRA. Vladmir Oliveira da; SANCHES. Samyra Haydêe Dal Farra Naspolini. A Reprodução do Paradigma Dogmático da Ciência do Direito no Ensino Jurídico e a Necessidade de Mudanças na Pesquisa Jurídica, que Permitam uma Efetiva Educação Jurídica. In: Educação Jurídica. Ed. Saraiva. 2013.

TARGINO, Graça. Novas tecnologias e produção científica: uma relação de causa efeito ou relação de muitos efeitos? Disponível em:

www.ufpe.br/snbu/mariatargino.doc. Acesso em: 11 fev 2019.

VALENTE, Joe Armando. Computadores e conhecimento: repensando a educação. Campinas, SP: UNICAMP, 1993.

WILLIAMSON, Andy. Getting ready for e democracy: A five-stage maturity model for Community ICT. Disponível em: http://www.public-olicy.unimelb.edu.au/ egovernance/papers/42_Williamson.pdf. Acesso em: 28 fev 2019. 